\title{
Article \\ In-Plane Fragility and Parametric Analyses of Masonry Arch Bridges Exposed to Flood Hazard Using Surrogate Modeling Techniques
}

\author{
Carlos Mendoza Cabanzo *, Mónica Santamaría (D), Hélder S. Sousa (D) and José C. Matos (D)
}

Citation: Mendoza Cabanzo, C.; Santamaría, M.; Sousa, H.S.; Matos, J.C. In-Plane Fragility and Parametric Analyses of Masonry Arch Bridges Exposed to Flood Hazard Using Surrogate Modeling Techniques. Appl. Sci. 2022, 12, 1886. https:// doi.org/10.3390/app12041886

Academic Editor: Jong Wan $\mathrm{Hu}$

Received: 26 January 2022

Accepted: 9 February 2022

Published: 11 February 2022

Publisher's Note: MDPI stays neutral with regard to jurisdictional claims in published maps and institutional affiliations.

Copyright: (C) 2022 by the authors. Licensee MDPI, Basel, Switzerland. This article is an open access article distributed under the terms and conditions of the Creative Commons Attribution (CC BY) license (https:// creativecommons.org/licenses/by/ $4.0 /)$.

\author{
Department of Civil Engineering, Institute for Sustainability and Innovation in Structural Engineering (ISISE), \\ University of Minho, 4800-058 Guimarães, Portugal; id8021@alunos.uminho.pt (M.S.); \\ hssousa@civil.uminho.pt (H.S.S.); jmatos@civil.uminho.pt (J.C.M.) \\ * Correspondence: pg41011@alunos.uminho.pt
}

\begin{abstract}
Natural disasters are unavoidable and can cause serious damage to bridges, which may lead to catastrophic losses, both human and economic. Therefore, the assessment of bridges exposed to these events is of paramount importance to identify possible mitigation needs. The objective of the present work is to present consistent tools that may allow us to obtain the failure probability of a masonry arch bridge under a flood event, leading to local scour. Surrogate models were implemented to ease the computational cost of the probabilistic analysis. Moreover, a stochastic parametric analysis based on the geotechnical properties of the soil components of masonry arch bridges located in Portugal was performed. The results show the failure mechanism of the masonry arch bridges when subjected to scour-induced settlements and the influence of soil density on the failure probability obtained for different flow discharge values and angles of attack. The presented methodology and derived fragility curves can be used to assess bridge performance under a flood event, thus providing useful information for bridge management and monitoring.
\end{abstract}

Keywords: masonry arch bridges; flood events; local scour; fragility curves; surrogate models

\section{Introduction}

Proper bridge management is vital to maintain a satisfactory performance level of the large stock of built infrastructures. Its main goal is to define optimal repair, maintenance, and replacement strategies for bridge inventory. Nonetheless, there are numerous challenges for achieving this goal since bridges are subjected to different demands, such as increasing traffic loads and exposure to harsh environmental conditions, which lead to serious deterioration processes that reduce their structural performance over time [1,2]. Therefore, the lack of inspections and inappropriate maintenance may result in partial or total bridge failures [3]. Moreover, the occurrence of extreme natural events (e.g., earthquakes, landslides, floods, scour, hurricanes, typhoons) has also caused sudden bridge collapses in the past. Among these natural causes, flood-induced scour has been identified as one of the predominant triggers of bridge failure worldwide [4].

Between the different bridge types, masonry arch bridges (MAB) are recognized as highly vulnerable to scour effects due to their rigid behavior, which is sensitive to settlements, and the fact that they were typically built on shallow footing foundations [5-7]. Furthermore, there is a reduction of the global load-carrying capacity of an MAB when the water level rises above the deck, thus making the arch barrel and surrounding fill saturated; the buoyancy effects reduce the self-weight contribution of the masonry and of the fill to strength capacity of the arch [8]. For these reasons, the safety assessment of MAB against flooding and scour effects is of utmost importance to identify possible mitigation plans.

When assessing bridge safety, the lack of information causes high uncertainties when representing the loads and material properties. Thus, by explicitly considering the uncer- 
tainties and implementing fully probabilistic approaches, the lack of information can be mitigated [9]. In this regard, fragility functions have become broadly used to represent the probability of exceeding an undesirable limit state for a given intensity of a hazard. Multiple methods have been used for the definition of fragility functions, especially in the field of seismic assessment (see [10] for an overview). Some key differences between each method may include but are not limited to the level of detail, type of failure mode, and the use of numerical simulations. Methods, such as the safety factor, use safety margins to assess uncertainties, which have the advantage of not using time-consuming numerical simulations [11]. Analytical approaches have also been implemented when there is a lack of damage information [12]. Conversely, numerical simulation methods can provide a detailed response of the structure, and when combined with regression methods, they can be applied to a great range of intensity measures. Nonetheless, this comes at the cost of more time-consuming numerical analyses [10].

Published literature on fragility functions for bridges exposed to flood events is less common than for other natural hazards, such as earthquakes (see [13] for an overview). Some efforts have been made to assess the combined effect of flood-induced scour on the seismic fragility of bridges (e.g., [14-16]). However, these studies account for scour as an aggravated condition for seismic fragility rather than as a collapse failure mechanism by itself. More recently, flood-related fragility curves for concrete bridges have been developed, considering multiple failure modes due to local scour, together with the action of additional demands, such as hydraulic forces, hydrodynamic pressure due to debris accumulation, and deterioration effects due to corrosion (e.g., [17-20]). Nevertheless, the methodologies implemented in these research efforts are case-specific and time-consuming due to the use of finite element modeling for probabilistic analysis, which hinders the possibility of applying them at a network level scale, i.e., for a large portfolio of assets [21]. Some research contributions have introduced surrogate modeling techniques into the probabilistic framework for quantifying the failure probability of bridges under flood hazards to overcome this issue $[22,23]$. Yet, there is limited research on the fragility modeling of MAB subjected to flood and scour effects using surrogate modeling.

The present work proposes a consistent framework to derive fragility curves associated with a failure mode of MAB under flood hazard using surrogate models for reducing computational costs. The framework includes random variables that affect both the bridge structural capacity and scour geometry. The proposed approach uses two-dimensional limit analysis models to predict ultimate load-carrying capacity, which has been effectively used in combination with probabilistic analysis for safety verification of $\operatorname{MAB}[9,21,24]$. Moreover, a parametric analysis is introduced into the framework to investigate the influence of the geotechnical properties of the riverbed and MAB backfill. This type of parametric analysis may serve as a starting point for network-level fragility analysis, where all the assets and their effects under a flood hazard can be efficiently considered, thus supporting the overall decision making and bridge management. For calibration and validation purposes, the proposed framework was used to obtain a flood fragility surface for a Portuguese MAB using river discharge as the hazard intensity measure associated with a given set of flow angles of attack.

This paper is divided into five sections. Section 2 presents the proposed framework for parametric fragility assessment of MAB under local scouring and the information regarding the case study used for the demonstration of the methodology. Section 3 describes the probabilistic analysis of local scour, bridge reliability, and sensitivity analysis, as well as information regarding the surrogate model implemented for the fragility analysis. Section 4 provides a parametric analysis based on variations in the geotechnical properties. Section 5 presents the conclusions drawn during this research and states the possible follow-up studies. 


\section{Methodology}

The framework depicted in Figure 1 shows the proposed methodology for a parametric fragility assessment of $\mathrm{MAB}$ under local scouring. Initially, a case study is defined, and the preliminary data is gathered from maintenance records, previous assessment studies, and rehabilitation projects performed on the case study [25]. Subsequently, a 2D numerical model is built based on the collected information using limit state-based software. In parallel, a scour analysis is performed, in which several random variables related to the scouring process are reviewed, assessed, and introduced for the computation of the probabilistic distribution of the scour depth [26]. For the probabilistic analysis, UQlab, a general-purpose Uncertainty Quantification framework running on MATLAB, was employed [27].

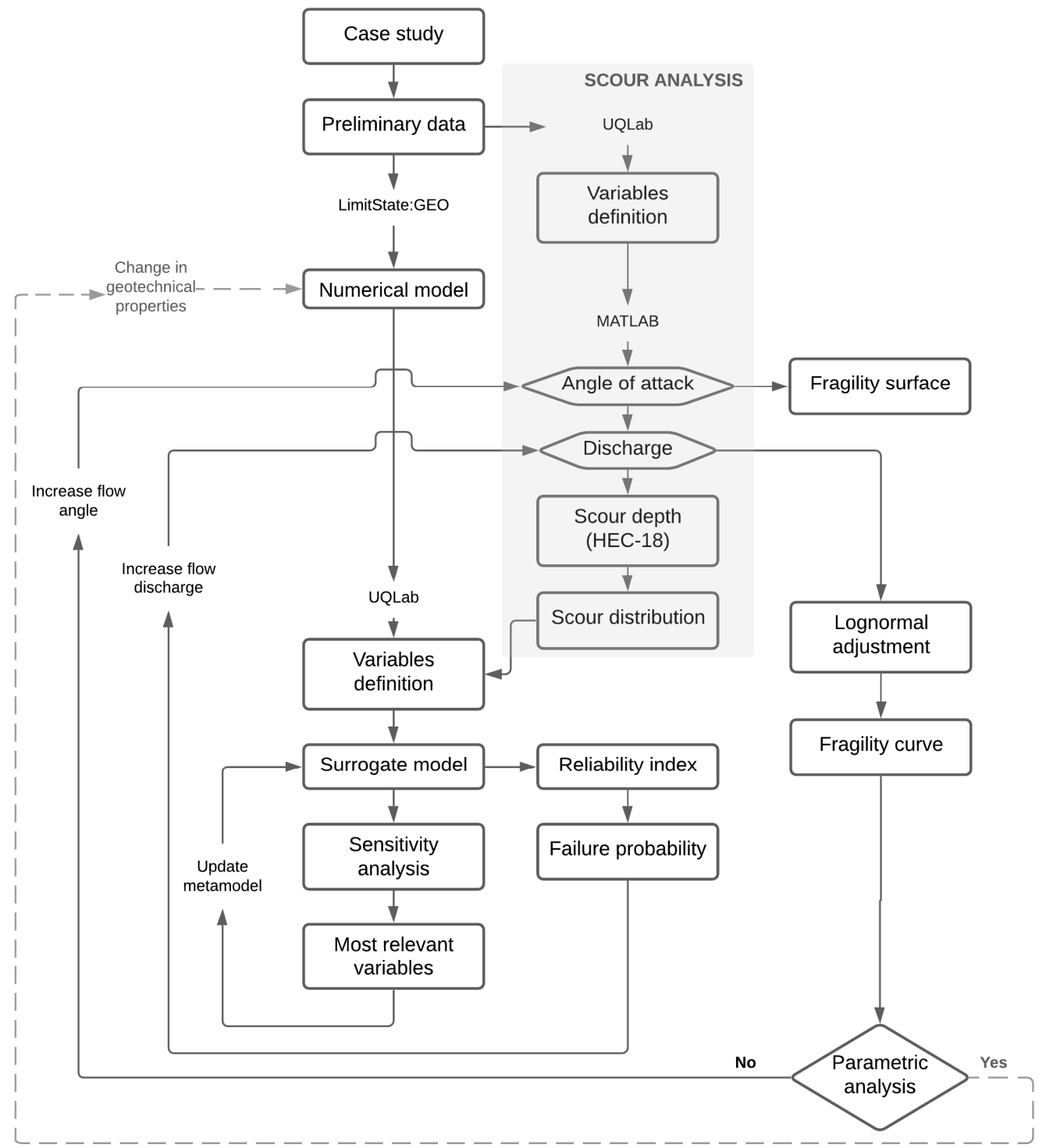

Figure 1. Framework for parametric fragility assessment of MAB under local scouring.

It should be noted that several scour depth prediction formulas are available in the literature (for an overview, refer to [28]). For the present study, the formulation from the Hydraulic Engineering Circular Number 18 (HEC-18) from the Federal Highway Administration is used to estimate the local scour depth at bridge piers [26]. The HEC-18 pier scour depth given in Equation (1) is computed based on the upstream flow depth $y_{0}$, pier geometry $D$, Froude number $F r$, flow velocity $V$, flow depth $y_{0}$, and four correction 
factors. The correction factors are related to pier shape $K_{1}$, angle of attack $K_{2}$, bed condition $K_{3}$ and sediment size $K_{4}[26]$.

$$
\frac{y_{s}}{y_{0}}=2.0 K_{1} K_{2} K_{3} K_{4}\left(\frac{D}{y_{0}}\right)^{0.65} F r^{0.43}
$$

Subsequently, in the variable definition stage, after scour analysis is performed, the physical properties used for describing the mechanical behavior of materials are considered. Then, a surrogate model is constructed, which is later used to perform a sensitivity analysis that identifies the most influential variables on the ultimate capacity of the bridge, which enables the reduction of the computational costs of the full probabilistic analysis $[9,24,29]$. Finally, the reliability index and the failure probability are computed using the subset simulation technique [30] by using the performance function, $G$, where $R$ and $S$ are the capacity and demand, respectively. Therefore, when the load actions overcome the loadcarrying capacities $(G<0)$, system failure $P_{f}$ is achieved:

$$
P_{f}=P(G<0)=P(R-S<0)
$$

The reliability index can be defined as the inverse of the coefficient of variation of the Cumulative Distribution Function of the limit state function [31,32]. In Equation (3), $\beta$ is the reliability index, $\Phi$ is the normal distribution and $P_{f}$ is the probability of failure of the structure.

$$
\beta=-\Phi^{-1}\left(P_{f}\right)
$$

Next, fragility analysis is performed using the discharge as the intensity measure. It should be noted that for increasing values of discharge, the probabilistic distribution of the scour depth, as well as the scour geometry, is recalculated. Subsequently, a lognormal adjustment is used to better represent and ease the implementation of the flood fragility curve in the decision-making process related to bridge performance [13].

Lastly, the procedure may be implemented for different flow angles of attack of the case study, which allows defining a fragility surface. Furthermore, geotechnical properties related to the soil materials of the case study may be changed, which allows a parametric analysis for assessing and identifying the influence of geotechnical parameters on the in-plane bridge fragility under local scouring from a case study.

\subsection{Case Study}

The case study "Vala do Carregado" is a railway masonry arch bridge located in Vila Franca de Xira, a city within the Lisbon district in Portugal (see Figure 2). The three-span bridge has a total span of around $30 \mathrm{~m}$, and it is supported by direct foundations. The earliest reports of the bridge date from 1881, when the bridge was built; after that, subsequent studies were performed where it was found that the bridge foundations presented poor soil conditions, and this was the reason why the bridge was replaced [25]. For that time, typical masonry arch bridges in Portugal did not, in general, present spans larger than $20 \mathrm{~m}$, and the thickness of its piers was between $1 / 3$ and $1 / 5$ of the span length [33]. For these reasons, the "Vala do Carregado" bridge is considered representative of the typical Portuguese railway masonry arch bridges susceptible to flood hazards.

\subsection{Numerical Model}

Preliminary data related to bridge dimensions, materials, and historical records were gathered from the Portuguese railway authorities (Infraestruturas de Portugal) [25]. A numerical model was built using a limit-state analysis software named LimitState:GEO [34], which has been commonly used to assess the capacity and failure of MABs, with fast and computational efficiency, while modeling the soil parts of the bridge and its interaction with other materials (e.g., concrete, masonry) [35-37]. By assuming that there is no failure (nor excessive deformation) in the spandrel walls, the bridge capacity will depend mainly 
on the arch barrel and the backfill. Therefore, $2 \mathrm{D}$ limit state analyses are sufficient and best suited for in-plane assessment of bridge reliability.

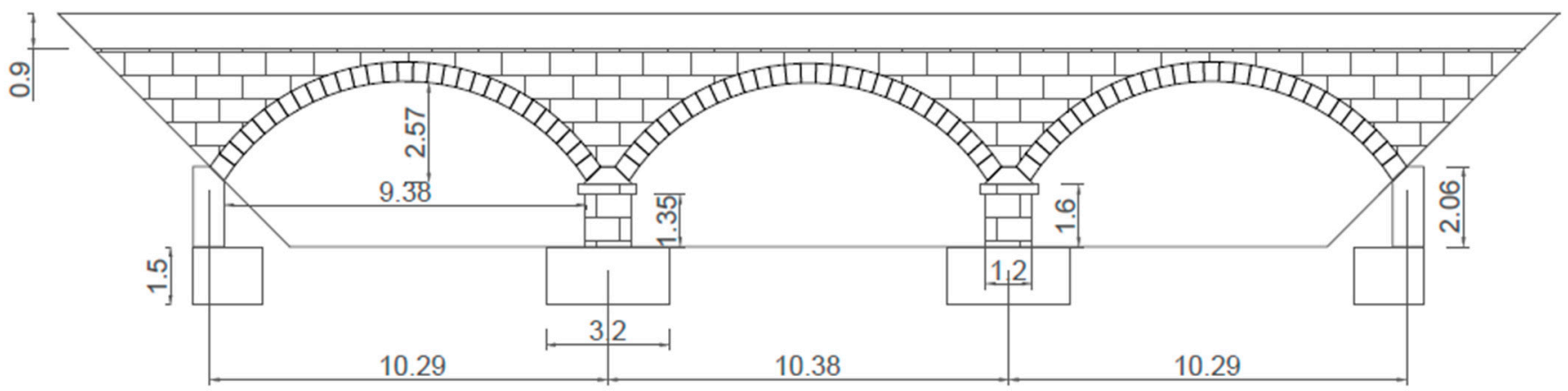

Figure 2. Case study (dimensions in $\mathrm{m}$ ).

Only the parameters defining the yield surface are required for the material models used by LimitState:GEO. The following models were used to define the different components of the case study (as shown in Figure 3): (i) a Mohr-Coulomb model was employed to represent the soil parts of the bridge; (ii) fully rigid blocks were used for modeling masonry blocks and foundations; (iii) cutoff materials were used to model joints, which allow modeling of tension cracks or crushing by limiting the tensile or compressive stress, respectively; and (iv) a derived material is used to define the soil/structure interaction by applying multipliers to the adjacent soil [34,35]. According to studies that have been made regarding the reliability of Portuguese MABs, which are based on the documentation and load models provided by Infraestruturas de Portugal, the used load model is composed of four-point loads spaced by $1.6 \mathrm{~m}$. Two distributed loads are also defined within the load model, but studies have shown that by not considering them, the most unfavorable case scenario is achieved [9,38]. Different positions for the selected loading pattern along the bridge length were considered, and it was concluded that the position that has the highest impact on the ultimate capacity is achieved when the load is applied at the center of the middle span. Moreover, movement along the horizontal direction was restricted to represent the restraint provided by the terrain, and fixed supports were assumed at the bottom edge of the model to represent a more competent soil layer.

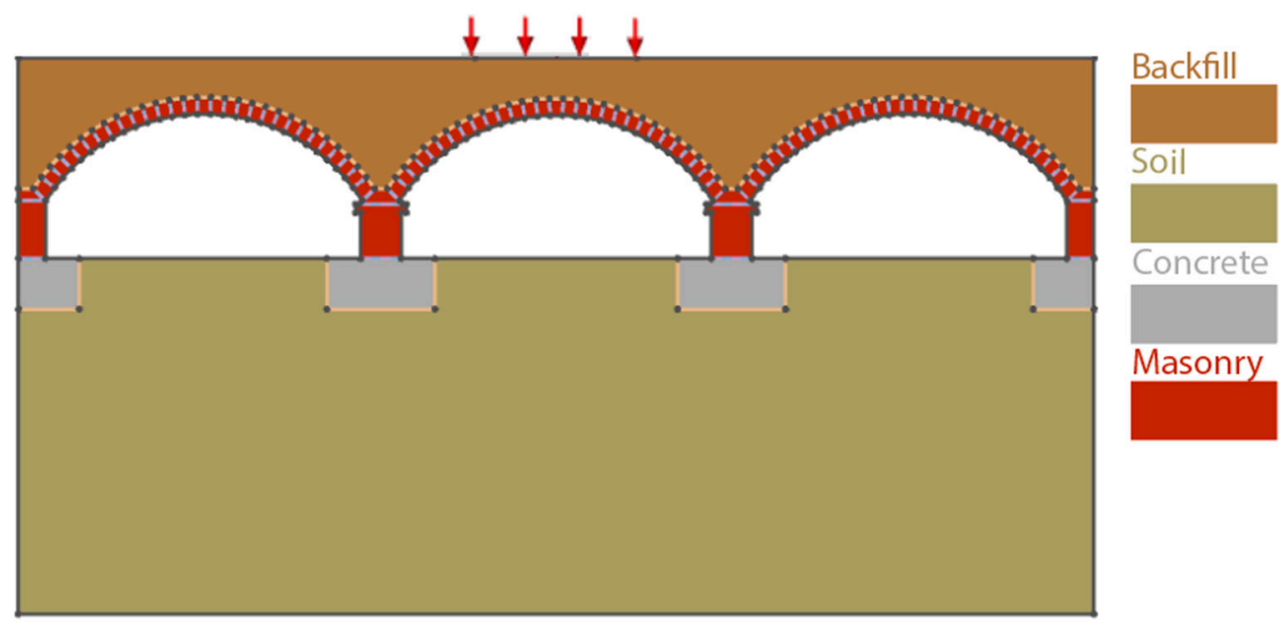

Figure 3. 2D limit state model in LimitState:GEO [30,35]. 


\section{Probabilistic Analysis}

\subsection{Scour Analysis}

Scouring can be formed around the pier, i.e., at the laterals of the pier, due to the bifurcation of the flow after impacting with the frontal (upstream) face of the pier [39]. Different scour profiles representing the incremental nature of the scouring process, both symmetrical and asymmetrical, have been used in the failure analysis of MABs, with shapes that are based on the soil's friction angle and the increasing water flow values $[5,18]$. Moreover, pier geometry, and more specifically, pier shape, directly affects the development of the scour profile around the pier. For instance, it was found that for piers with sharp triangular noses, lateral scour occurs symmetrically and overall produces less turbulence strength and consequently less scour [39].

In this study, different scour profile shapes are used to represent the propagation of each level of scour depth (see Figure 4); Stage 0 shows the case with no scour, and stages 1 to 3 show values of scour depth smaller, equal, and larger than the footing thickness $\left(F_{t}\right)$, respectively. It was found that for scour profiles where the scour depth does not erode the soil beneath the foundation base, its influence on the structural response of the MABs is neglectable [5-7]. Nevertheless, when that limit is surpassed, settlement increases, leading to cracking of the arch barrel.

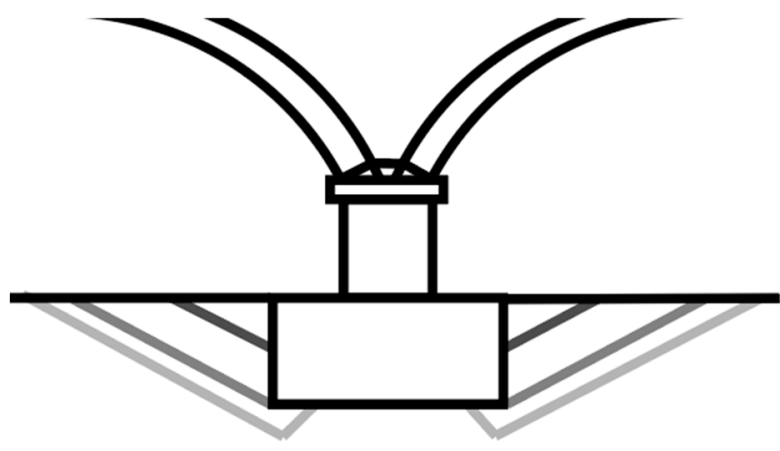

(a)

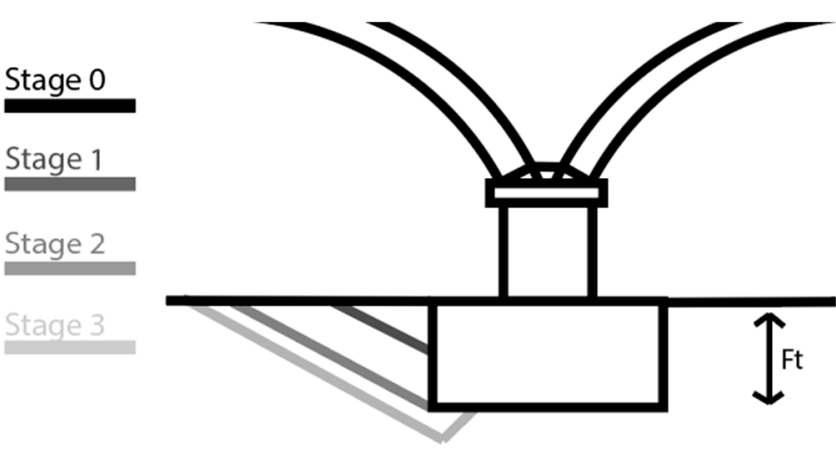

(b)

Figure 4. Stages of the scour depth when compared to the footing thickness $\left(F_{t}\right)$ for the different scour scenarios: (a) symmetric; (b) asymmetric.

The variables involved in the computation of scour depth are gathered; then, the ones considered random are introduced in the UQlab software, which was implemented using a script with its probabilistic distribution [27]. Next, the Monte Carlo sampling method is used for its ability to factor the full range of values of the uncertainties of the parameters to obtain a 1000 value sample, which will be used to introduce randomness to the computation of the scour depth using the HEC-18 formulation [40]. When an angle of attack is defined, asymmetric scour is being considered, therefore creating a dragging force on the pier surface, which is assumed to be rectangular due to flow velocity being constant along the flow depth [41]. Finally, model uncertainties are introduced to account for the reliability of the HEC-18 formulation [26,42]. Parameter uncertainties were considered in the assessment of the scour depth. These parameters are related to geometric parameters, such as riverbed conditions, width, longitudinal slope, pier width and length, and Manning coefficient [40]. Flow angle, which is formed between the main direction of the flow and pier alignment, was defined as follows: $0^{\circ} ; 5^{\circ} ; 10^{\circ} ; 20^{\circ} ; 30^{\circ}$; and $45^{\circ}$ [43], whereas the following values for the flow discharge in $\mathrm{m}^{3} / \mathrm{s}$ were used: $1 ; 5 ; 10 ; 25 ; 50 ; 100 ; 150$; and 200, being addressed as Q1; Q2; Q3; Q4; Q5; Q6; Q7; and Q8, respectively. In Table 1, the probabilistic distributions and parameters of each random variable are presented. 
Table 1. Random variables for the scour analysis.

\begin{tabular}{|c|c|c|c|c|c|c|}
\hline ID & Description & Nominal Values & Units & CV $(\%)$ & Type & Reference \\
\hline B & River width & 15.00 & $\mathrm{~m}$ & 5 & Gaussian & [40] \\
\hline $\mathrm{D}$ & Pier width & 2.00 & $\mathrm{~m}$ & 5 & Gaussian & [40] \\
\hline $\mathrm{L}$ & Pier length & 10.50 & $\mathrm{~m}$ & 5 & Gaussian & [40] \\
\hline $\mathrm{n}$ & Manning coeff & 0.0020 & - & 28 & Lognormal & [40] \\
\hline $\mathrm{s}$ & Longitudinal slope & 0.0750 & - & 5 & Lognormal & [40] \\
\hline$K_{3}$ & Bed condition coeff & 1.10 & - & 5 & Uniform & [40] \\
\hline$\lambda(\mathrm{MU}\{\mathrm{XE}$ “MU” $\})$ & Model uncertainty & 0.82 & - & 23 & Gaussian & [42] \\
\hline
\end{tabular}

A probabilistic distribution for the flow depth was obtained for each one of the considered discharge values, and it was observed that when the discharge value increases, the mean value of the flow depth also increases. Nevertheless, the value corresponding with the $95 \%$ quantile was assumed to consider the most unfavorable scenario [8]. Finally, failure for both profile types (symmetrical and asymmetrical) was achieved due to equilibrium loss. As expected, the behavior of the scour depth is like the one observed for the flow depth in which the mean value of the scour depth increases when the discharge increases, as can be seen from Figure 5 .

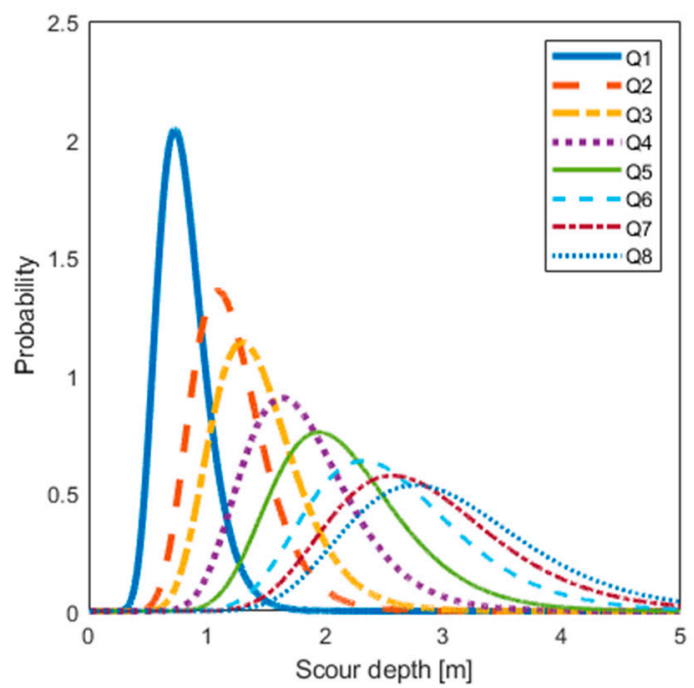

(a)

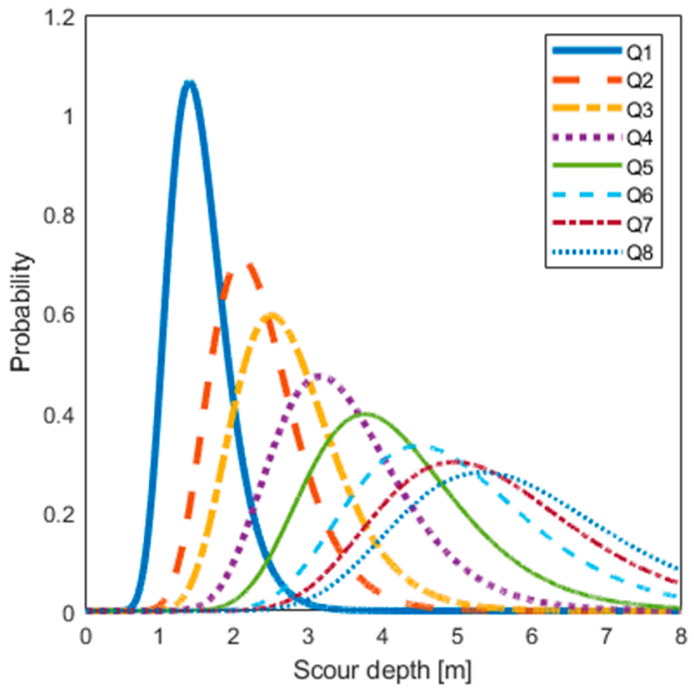

(b)

Figure 5. Fitted Gumbel distributions for the scour depth for each discharge value (Q1-Q8) for the cases with the value of the flow angle of attack of: (a) $0^{\circ}$ (symmetric scour); (b) $20^{\circ}$ (asymmetric scour).

\subsection{Reliability Analysis}

Reliability analysis takes advantage of the capabilities of the metamodeling technique to optimize computational resources [29]. First, a set of random variables (see Table 2) is assessed and introduced to UQlab. Then, by using the Latin Hypercube Sampling method, an experimental design (i.e., collection of known input-output pairs) is obtained. Before performing a sensitivity analysis, a surrogate model is introduced that represents the structural behavior of the case study by using a small experimental design [29]. Then, after the sensitivity analysis is performed, it is possible to identify the variables with the highest impact on the load-carrying capacity of the structure, and a new experimental design is obtained based on the relevant variables, which will later be used to update the surrogate model [24]. Subsequently, the capacity curve of the structure for a given discharge value is obtained and compared with the loading curve to compute the reliability index by using the subset simulation technique [44]. Additionally, model uncertainties are being considered 
in the process to obtain the failure probability of the structure [45]. Finally, the process is repeated for each value of flow discharge, and the angle of attack herein is considered to build the fragility curve.

Table 2. Random variables for the reliability analysis.

\begin{tabular}{cccccccc}
\hline ID & Description & Element & $\begin{array}{c}\text { Nominal } \\
\text { Values }\end{array}$ & Units & CV (\%) & Type & Reference \\
\hline$F A_{S}$ & Friction angle & Soil & 34.61 & $\circ$ & 10 & Lognormal & {$[45]$} \\
$S D_{S}$ & Saturated density & Soil & 20.50 & $\mathrm{kN} / \mathrm{m}^{3}$ & 5 & Lognormal & {$[45]$} \\
$D D_{S}$ & Dry density & Soil & 17.50 & $\mathrm{kN} / \mathrm{m}^{3}$ & 5 & Lognormal & {$[45]$} \\
$S D_{B}$ & Saturated density & Backfill & 19.00 & $\mathrm{kN} / \mathrm{m}^{3}$ & 5 & Lognormal & {$[46]$} \\
$C_{B}$ & Cohesion & Backfill & 10.00 & $\mathrm{kPa}$ & 10 & Lognormal & {$[46]$} \\
$F A_{B}$ & Friction angle & Backfill & 21.06 & $\circ$ & 10 & Lognormal & {$[24]$} \\
$D D_{B}$ & Dry density & Backfill & 17.00 & $\mathrm{kN} / \mathrm{m}^{3}$ & 5 & Lognormal & {$[24]$} \\
$D_{C}$ & Density & Concrete & 25.00 & $\mathrm{kN} / \mathrm{m}^{3}$ & 10 & Gaussian & {$[47]$} \\
$D_{M}$ & Density & Masonry & 16.00 & $\mathrm{kN} / \mathrm{m}^{3}$ & 10 & Gaussian & {$[48]$} \\
\hline
\end{tabular}

To better determine the influence of the soil's mechanical properties when performing a reliability analysis, their interaction should be included. The cross-correlation coefficient $(\rho)$ and different values of the correlation coefficient for different combinations of soil parameters (e.g., unit weight, cohesion, and angle of friction) have been identified and implemented for the case study $[49,50]$.

\subsubsection{Surrogate Model}

Comparisons between different surrogate models have been conducted, in which a combination between kriging metamodels and subset simulation (AK-SS) has been proven to be efficient in describing non-linear limit state functions, allowing a great representation of the behavior of the function using an experimental design of 19 models [29]. Therefore, an experimental design of 20 runs generated using the Latin Hypercube Sampling Method was used. Then, a Kriging surrogate model using UQlab was created and validated based on the random variables previously defined. The surrogate model uses a universal trend type, an anisotropic ellipsoidal Matérn 5/2 correlation function, used to define the Gaussian process and cross-validation estimation method. For the validation of the surrogate model, two different sources of error estimation were implemented: the leave one out method and a validation experimental design set of 10 runs using LHS.

\subsubsection{Sensitivity Analysis}

To better comprehend the impact of each variable on the load-carrying capacities of the structure, a sensitivity analysis was performed using UQlab. Due to the correlation between some variables, the analysis of covariance (ANCOVA $\{$ XE "ANCOVA" $\}$ ) was used to produce helpful sensitivity indices for both correlated and uncorrelated input variables [51]. As expected, the parameters with the most influence over the load-carrying capacity are the ones used to describe the backfill soil due to its high contribution to the bridge capacity when analyzing the in-plane behavior (and excluding the spandrel walls) [52]. Next in relevance is the scour profile (e.g., shape, depth), which has a considerable impact on the load-carrying. Lastly, the contribution from the remaining parameters can be neglected when compared with other parameters. As shown in Figure 6, the impact from the scour variable is mainly uncorrelated, and the ones related to the backfill are more heavily influenced by the correlation among its input variables (i.e., the magnitude of the correlated indices is closer to the total first-order indices). 


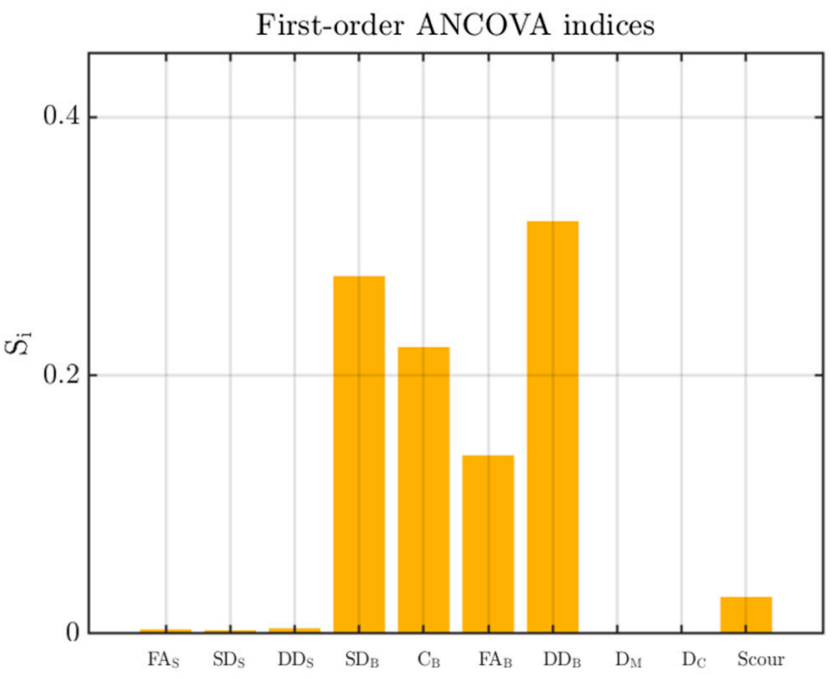

(a)

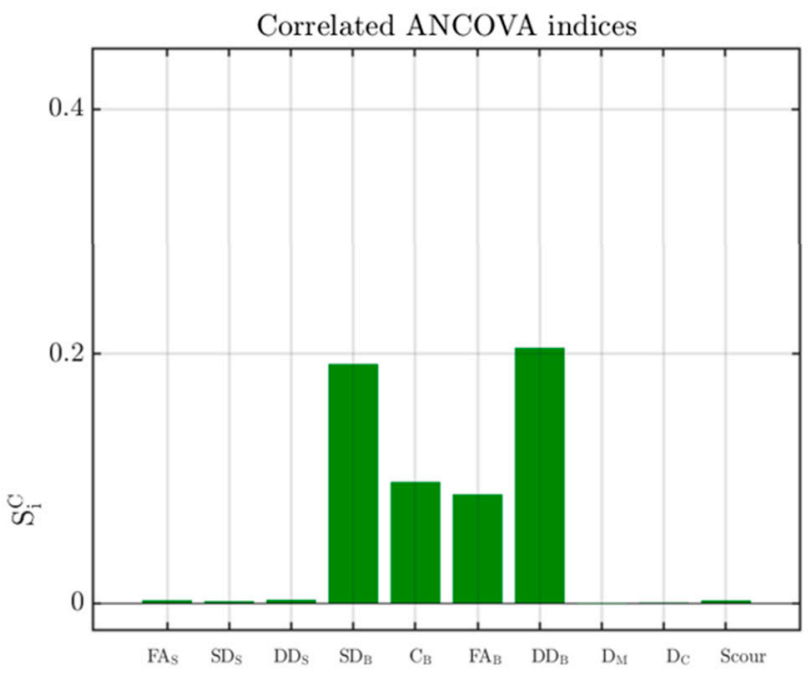

(b)

Figure 6. ANCOVA indices: (a) First order; (b) correlated.

The surrogate model, based on the relevant variables, is used to evaluate an experimental design of 10,000 simulations using the Monte-Carlo (MC\{XE "MC" $\}$ ) sampling method, which will capture the capacity curve. Then, a Gumbel minimum distribution was fitted based on the generated histogram of adequacy factors (i.e., number of load increments that the structure can withstand without collapsing based on the acting load), which allowed us to define the resistance curve, $R$. The loading curve is based on the data collected from measurements performed by the Portuguese statistical institute (INE $\{X E$ "INE" $\}$ ) of railway frequency and magnitude. The loading curve, $S$, was defined using existing data fitted to a Gumbel distribution, which is described by a mean equal to $184.41 \mathrm{kN}$ and a COV of 9.06\% [9]. The limit state function (2) was introduced to UQlab to evaluate the reliability of the structure by using the probabilistic distribution of both loading and capacity curves.

Additionally, model uncertainties for limit state models (defined by a Gaussian distribution of mean 1 and COV 15\%) were also considered based on the recommendations of the Joint Committee on Structural Safety (JCSS $\{$ XE "JCSS" $\}$ ) model code for modeling shallow foundation stability with homogeneous soil profiles [45]. To obtain the reliability index of the structure for a given discharge value, traditional methods like MC may require numerous simulations to converge with a satisfactory level of accuracy. Therefore, subset simulation techniques are employed herein to overcome this limitation by solving simpler reliability problems with intermediate thresholds [44]. Once the reliability analysis is completed, the failure probability and reliability index are obtained for each discharge value and flow angle.

Figure 7 shows the reliability index for different values of flow discharge and angle of attack, in which it can be observed that the reliability decreases with each increment of both parameters. The effect of the angle of attack over the bridge reliability was expected due to its influence over the hydrodynamics around the structure, which is not only evidenced in the HEC-18 formulation (1) but also by previous research made on the effects of flow characteristics on masonry structures, where the effects of the angle of attack over the overpressure are exhibited in the results from experimental tests [53]. For each of the different angles studied, two behaviors can be observed. The first is that the decrease in reliability for each increment in discharge is abrupt, while the second behavior of a more gradual reduction in the reliability is observed when most of the scour depth values were lower than the foundation thickness. Moreover, when considering extreme conditions of high discharge and/or high angles of attack, the reliability index may decrease below 0 , which indicates a failure probability higher than 0.5. Finally, when compared with the target reliability (i.e., $\beta_{\text {target }}=4.3$ corresponding to a failure probability bellow $10^{-5}$ ) for 
structures with consequences involving high human and economic losses, according to the NP 1990 [54], it may be concluded that the structure may not be within the safety levels when facing flooding events.

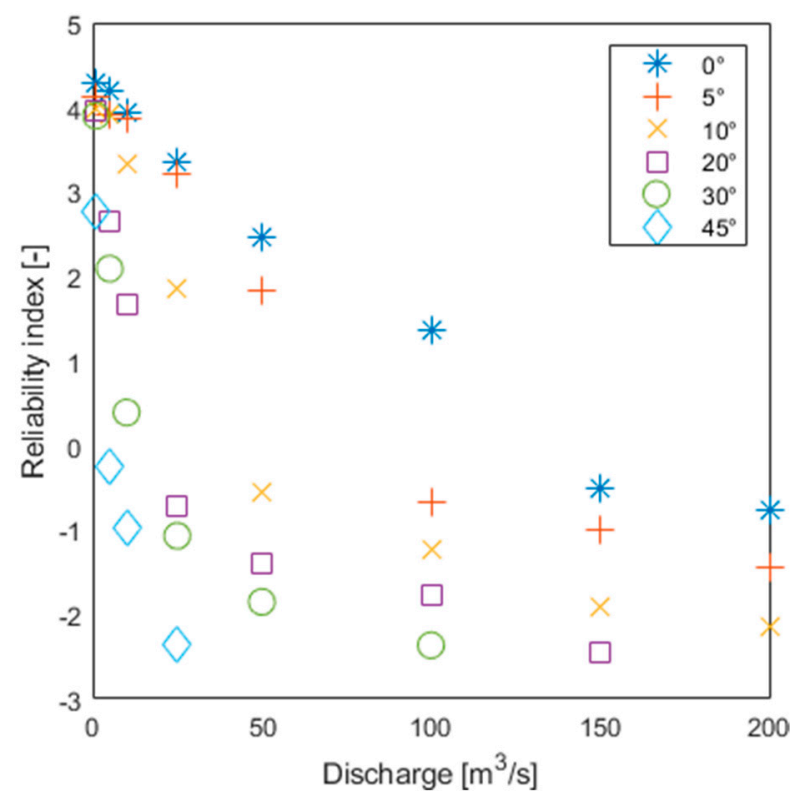

Figure 7. Reliability index of the case study for each discharge value (Q1-Q8) considering different flow angles of attack.

\subsection{Fragility Analysis}

Fragility functions are commonly used to correlate a given hazard, represented by an intensity measure, with expected physical damage (e.g., collapse) by using exceedance probability. Moreover, they are useful due to the possibility of introducing uncertainties in both capacity and demand while also providing the reliability of a structure over a range of loads expressed commonly by a lognormal distribution [13]. Flood-related fragility curves can also be used to assist quality control strategies before, during, and after a flood event [22]. Then, a lognormal adjustment is performed to obtain the coefficients of a lognormal distribution for fragility curve that fits the failure probabilities previously found. A script is employed to obtain the coefficients, which is based on the generalized linear model (GLM\{XE “GLM"\}). For this application, the generalized linear regression model is used, in which the response (dependent variable) is expressed as a linear function of all predictors (independent variables) [55].

\subsubsection{Damage Limit State for Fragility Analysis}

The numerical model used for the evaluation of the bridge capacity is based on a limit state analysis, where the capacity is given by a factor of the reference load, which in this case is the railroad load previously defined. Therefore, the fragility curves obtained represent the damage limit state of collapse. Figure 8 shows the differences between the different collapse mechanisms found at different stages of the scouring process. Among the different scour stages, the failure mode remains practically the same, i.e., in each case, failure of the backfill is achieved by incrementing the railroad load applied at surface level. Moreover, as can be observed for the cases in which the scour depth surpasses the $F_{t}$, failure of the soil underneath the foundation is also achieved. Moreover, failure at the riverbed is reached due to the mobilization of the foundation. Meanwhile, both arch failures show the characteristic shape of the hinging mechanism [56]. 


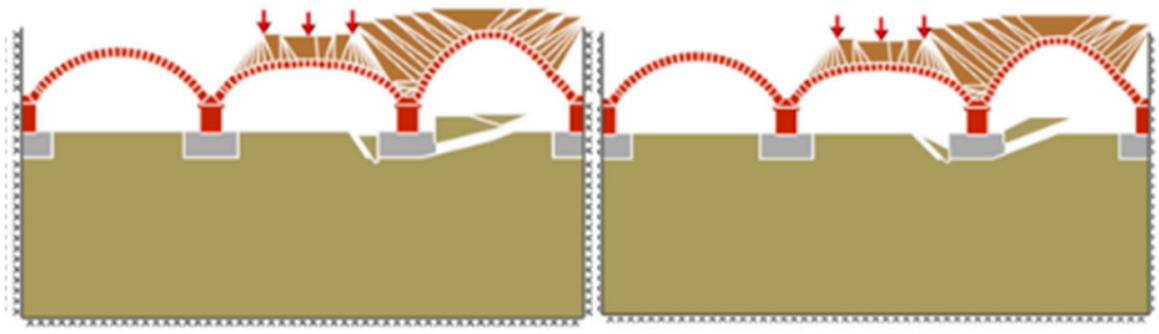

(a)

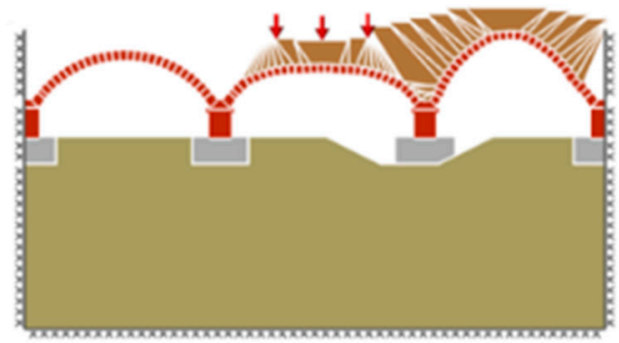

(c) (b)

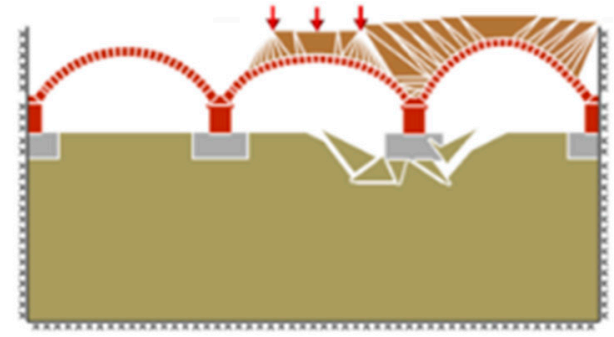

(d)

Figure 8. Collapse mechanisms at different stages of the scouring process with respect to the footing thickness $\left(F_{t}\right)$ : (a) Stage 0: no scour; (b) Stage 1: scour depth smaller than $F_{t}$; (c) Stage 2: scour depth equal to $F_{t} ;(\mathbf{d})$ scour depth larger than $F_{t}$.

\subsubsection{Fragility Curves}

It can be observed from Figure 9 that the capacity of the bridge decreases with each increment of the discharge value, which directly increases the mean value of the scour depth. Therefore, higher values may cause problems with extensive settlements of the bridge, which may induce instability on the arch barrel and consequently bridge collapse [5]. As expected, the loss of bearing capacity for discharge values where most of the scour depth values are lower than the $F_{t}$ is minor, thus causing a slight decrease in the bridge reliability index [5]. For the symmetric scour process, it can be observed that for discharge values below $50 \mathrm{~m}^{3} / \mathrm{s}$, the failure probability is rather small, and it only reaches an exceedance probability near 1 for discharge values higher than $400 \mathrm{~m}^{3} / \mathrm{s}$.

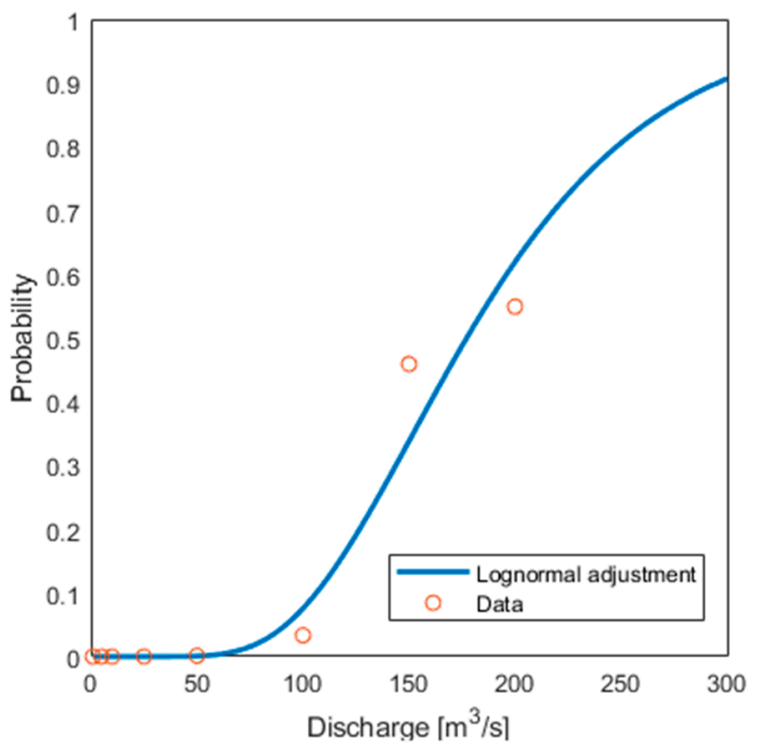

Figure 9. Fragility curve for the case study for a flow angle of attack of $0^{\circ}$. 
Before analyzing the fragility curves for flow angles different from $0^{\circ}$, it is important to understand that the effect of a skewed flow not only affects the bridge stability due to the increased rate of scour around the bridge but also due to the uncertainties associated with changes in flood flow $[43,57]$. Figure 10 shows the fragility surface for the case study, in which it can be observed that the failure probability increases with the discharge and with the angle of attack. For the asymmetric scouring process, when compared with the symmetric scouring process, there is an increased failure probability, particularly for the range when the latter has a small failure probability (i.e., discharge values below $50 \mathrm{~m}^{3} / \mathrm{s}$ ). Even so, for the most critical scenarios, where the angle of attack is higher than $20^{\circ}$, the failure probability is closer to 1 for the same range. It can be concluded that the angle of attack decreases the bridge reliability and that it is more sensitive to changes in discharge. This is expected due to asymmetric scouring having higher mean values of scour depth than symmetric scour [39].

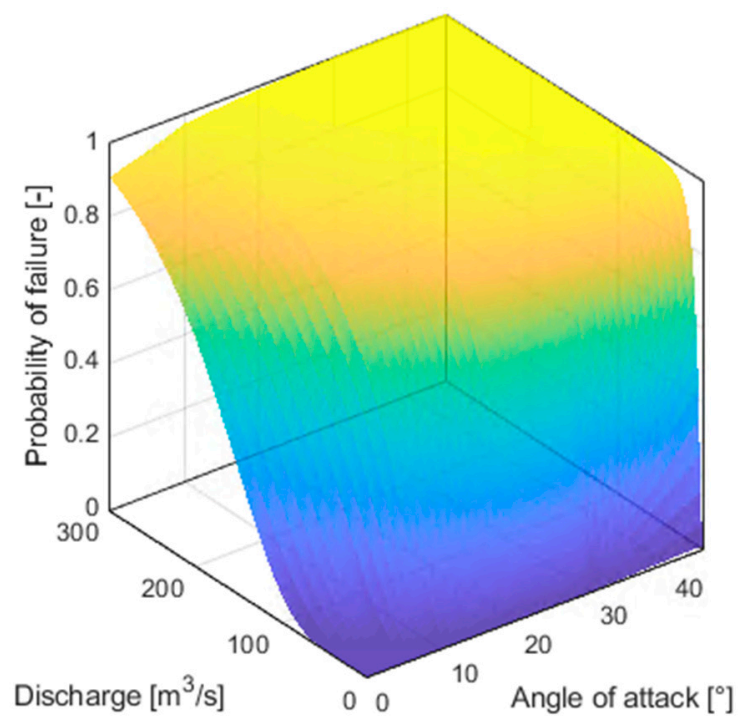

(a)

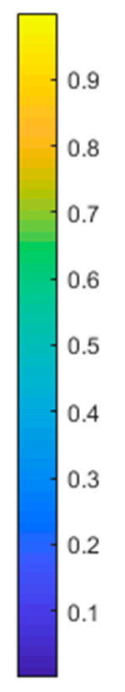

Figure 10. Fragility surface: (a) 3D plot; (b) Contours.

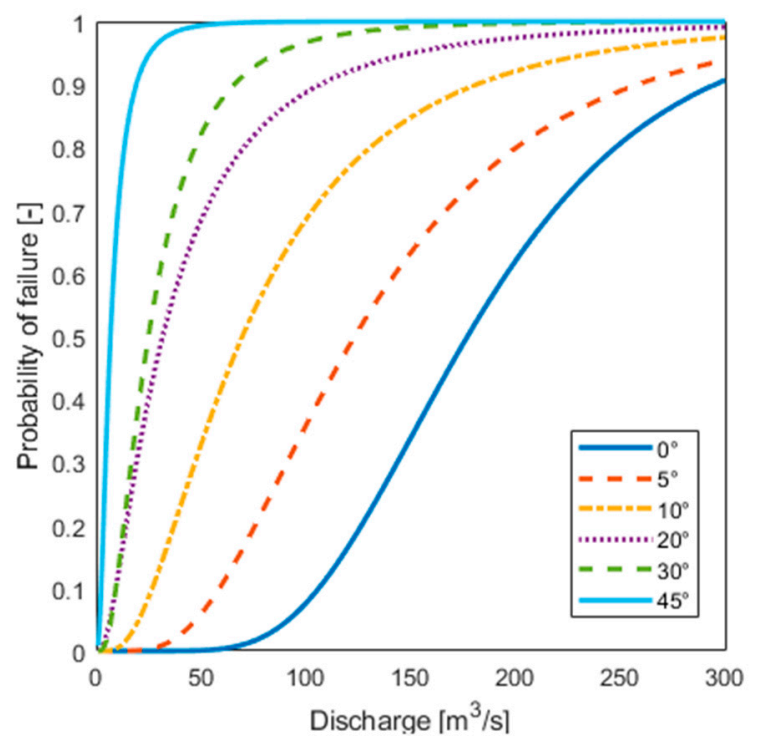

(b)

\section{Parametric Analysis}

As previously mentioned, the case study represents the typical characteristics of a Portuguese masonry arch bridge in a railroad network [33]. Nevertheless, there may be key differences that may influence the bridge response to flood-related effects. Thus, a parametric study was performed by changing the geotechnical properties of the bridge's soil materials, such as the stiffness of the soil in which the foundation is settled and the backfill. Even though the influence of the mechanical properties of the material was partially evaluated in the previous section, the influence of the quality of the material will be further analyzed. The different values for the mechanical characteristics of the three types of soils were obtained from the JCSS model code [45], and the selected soil types are assumed as non-cohesive sand with uniform grain size and medium plastic inorganic cohesive soil for the soil beneath the foundation and the backfill, respectively (see Table 3). The difference between all three densities can be observed in the difference in both saturated and dry densities and the friction angle and cohesion regarding the backfill mechanical properties [45]. It is worth mentioning that the case study previously discussed is considered the base scenario for both parametric analyses, namely medium (see Figure 11). 
Table 3. Random variables for the parametric analysis.

\begin{tabular}{ccccccccc}
\hline ID & Description & Element & Type & Nominal Values & Units & CV (\%) & Type & Reference \\
\hline$F A_{S}$ & Friction angle & Soil & Dense & 37.42 & $\circ$ & 10 & Lognormal & {$[45]$} \\
$S D_{S}$ & Saturated density & Soil & Dense & 21.50 & $\mathrm{kN} / \mathrm{m}^{3}$ & 5 & Lognormal & {$[45]$} \\
$D D_{S}$ & Dry density & Soil & Dense & 18.50 & $\mathrm{kN} / \mathrm{m}^{3}$ & 5 & Lognormal & {$[45]$} \\
$F A_{S}$ & Friction angle & Soil & Loose & 31.59 & $\circ$ & 10 & Lognormal & {$[45]$} \\
$S D_{S}$ & Saturated density & Soil & Loose & 19.50 & $\mathrm{kN} / \mathrm{m} 3$ & 5 & Lognormal & {$[45]$} \\
$D D_{S}$ & Dry density & Soil & Loose & 15.50 & $\mathrm{kN} / \mathrm{m}^{3}$ & 5 & Lognormal & {$[45]$} \\
$S D_{B}$ & Saturated density & Backfill & Dense & 20.00 & $\mathrm{kN} / \mathrm{m}^{3}$ & 5 & Lognormal & {$[45]$} \\
$C_{B}$ & Cohesion & Backfill & Dense & 20.00 & $\mathrm{kPa}$ & 10 & Lognormal \\
$F A_{B}$ & Friction angle & Backfill & Dense & 22.78 & $\circ$ & 10 & Lognormal & {$[45]$} \\
$D D_{B}$ & Dry density & Backfill & Dense & 18.00 & $\mathrm{kN} / \mathrm{m}^{3}$ & 5 & Lognormal & {$[45]$} \\
$S D_{B}$ & Saturated density & Backfill & Loose & 18.00 & $\mathrm{kN} / \mathrm{m}^{3}$ & 5 & Lognormal & {$[45]$} \\
$C_{B}$ & Cohesion & Backfill & Loose & 5.00 & $\mathrm{kPa}$ & 10 & Lognormal & {$[45]$} \\
$F A_{B}$ & Friction angle & Backfill & Loose & 19.29 & $\circ$ & 10 & Lognormal & {$[45]$} \\
$D D_{B}$ & Dry density & Backfill & Loose & 16.00 & $\mathrm{kN} / \mathrm{m}^{3}$ & 5 & Lognormal & {$[45]$} \\
\hline
\end{tabular}

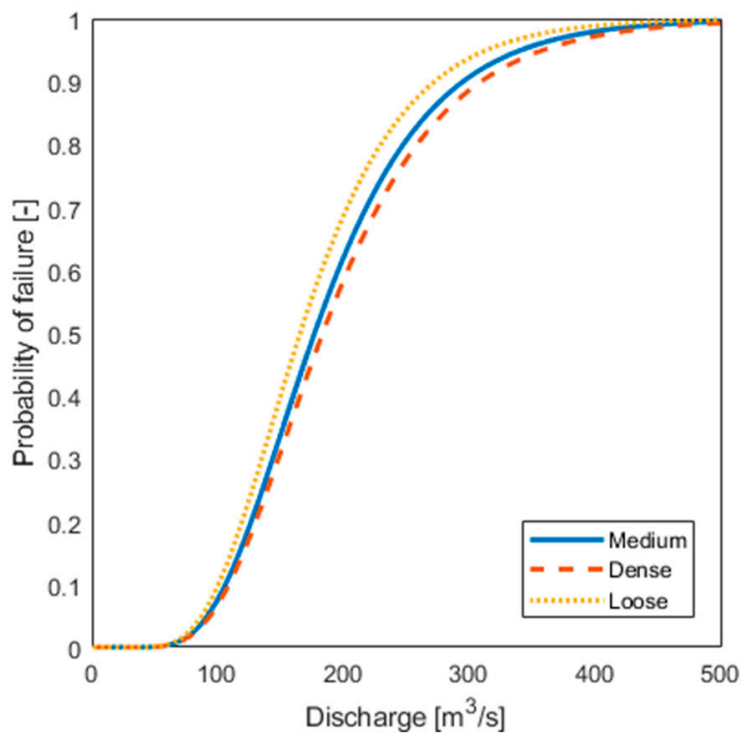

(a)

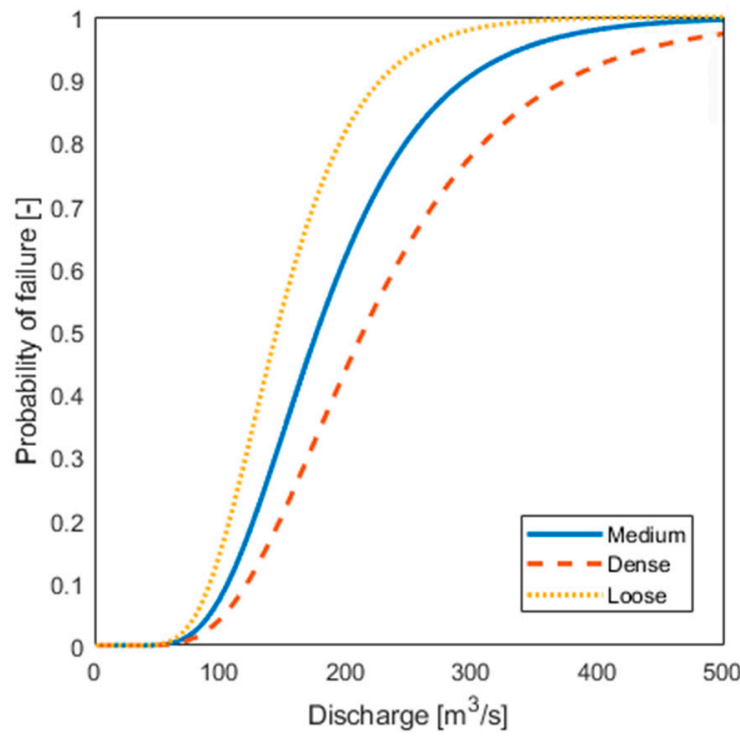

(b)

Figure 11. Fragility curves based on the geotechnical uncertainties of: (a) soil beneath the foundation; (b) backfill.

As expected in both scenarios, the loose soil presents higher failure probabilities when compared with more dense soils, especially when variations on the backfill are being assessed. This was expected due to the strong influence of the backfill on the overall in-plane bridge loading capacity [52]. Finally, a large increase in the failure probability can be seen for values higher than $100 \mathrm{~m}^{3} / \mathrm{s}$, in which the water is found above the bridge, and the scour depth forms mainly below the foundation [8]. It is possible to conclude that soil density affects the overall vulnerability of the bridge. Moreover, for extremely low and high values of discharge, the influence of the soil density is not as notorious as for the other values.

\section{Conclusions}

The present study proposed an efficient framework for the fragility assessment of in-plane MAB subject to flood-induced scour by integrating metamodeling techniques with limit state analysis. The significance of this research is that it allows us to expand the knowledge regarding MAB behavior under flooding events and ease the computational process related to performing fragility analyses. This latter advancement enables infrastruc- 
ture managers to assess the safety of a large stock of MAB more efficiently and therefore enhance the decision-making process by supporting the prioritization of maintenance and replacement strategies within the transportation network. The proposed methodology was applied to a case study, the "Vala do Carregado" bridge located in Portugal, and flood fragility curves were derived for different scour scenarios. Furthermore, a fragility surface was obtained for different flow discharge and angle of attack values, which may affect bridge reliability. Based on the obtained results, the following conclusions can be made:

- The sensitivity analysis allowed identification of the strong influence of geotechnical parameter uncertainty on the bridge response. The most relevant variables when assessing the bridge in-plane capacity were the backfill mechanical properties, which were validated by the literature $[18,52]$.

- The bridge reliability decreased with each increment of the flow discharge. However, the loss of bearing capacity for values of discharge where most of the scour depth values were lower than the $F_{t}$ was slight when compared with higher discharge values. Safety levels are met if the reliability of the structure is higher than the target reliability (i.e., $\beta_{\text {target }}=4.3$ corresponding to a failure probability bellow $10^{-5}$ ) for structures with consequences involving high human and economic losses, according to NP 1990 [54]. A decrease of the reliability index below the safety levels was identified for cases in which most of the values obtained for scour depth were below the foundation thickness.

- In all scenarios, failure probability increased with the flow discharge due to its significance on the estimation of the scour depth. Furthermore, it was observed that the likelihood of bridge failure was increased when the skewed flow was considered, in which the uncertainties associated with changes in the flow affected bridge stability due to the increased magnitude of the predicted scour depth [43,57].

- From the parametric study, it was observed that uncertainties regarding the mechanical properties of the backfill had the most influence on the bridge response under flooding events. Essentially, looser soils were more prone to have higher failure probabilities for a given discharge value than more dense soils, which is also true when uncertainties in the stiffness of the soil beneath the foundation are being considered.

- Fragility analysis based on numerical models and probabilistic analysis can be computationally expensive. Thus, the computational cost may be reduced by employing surrogate modeling techniques aided by a sensitivity analysis, providing a satisfactory level of reliability using smaller experimental designs.

- Flood fragility curves can be useful in aiding and providing valuable information that can be implemented into the bridge management decision-making process, thus reducing the bridge failure probability under flood-related events by applying maintenance and mitigation alternatives [22].

Finally, one of the limitations of the present study is that the limit analysis model used assumes an in-plane failure mode disregarding the out-of-plane behavior of MABs. As a follow-up study, the inclusion of the out-of-plane failure modes, which will allow the assessment of the full behavior of the MABs subject to local scouring processes, is highly recommended. Moreover, other failure modes related to flood events should also be included to expand upon a more general framework to develop fragility curves. Lastly, it is also important to acknowledge the impact of climate change and multi-hazard effects to better support asset management.

Author Contributions: Conceptualization, C.M.C. and M.S.; methodology, C.M.C.; software, C.M.C.; validation, C.M.C. and M.S.; formal analysis, C.M.C.; investigation, C.M.C. and M.S.; resources, M.S., H.S.S. and J.C.M.; data curation, M.S.; writing—original draft preparation, C.M.C.; writing—review and editing, M.S. and H.S.S.; visualization, C.M.C.; supervision, J.C.M.; project administration, H.S.S.; funding acquisition, M.S., H.S.S. and J.C.M. All authors have read and agreed to the published version of the manuscript.

Funding: This work was partly financed by FCT/MCTES through national funds (PIDDAC) under the R\&D Unit Institute for Sustainability and Innovation in Engineering Structures (ISISE), under 
reference UIDB/04029/2020. The second author would like to thank FCT-Portuguese Scientific Foundation-for research grant SFRH/BD/144749/2019. This project has received funding from the European Union's Horizon 2020 research and innovation programmed under grant agreement No 769255. This document reflects only the views of the author(s). Neither the Innovation and Networks Executive Agency (INEA) nor the European Commission is in any way responsible for any use that may be made of the information it contains.

Institutional Review Board Statement: Not applicable.

Informed Consent Statement: Not applicable.

Data Availability Statement: The data presented in this study are available upon a request from corresponding author.

Conflicts of Interest: The authors declare no conflict of interest.

\section{References}

1. Zambon, I.; Vidović, A.; Strauss, A.; Matos, J. Condition prediction of existing concrete bridges as a combination of visual inspection and analytical models of deterioration. Appl. Sci. 2019, 9, 148. [CrossRef]

2. Ariza, M.S.; Zambon, I.; Sousa, H.S.; Campos e Matos, J.A.; Strauss, A. Comparison of forecasting models to predict concrete bridge decks performance. Struct. Concr. 2020, 21, 1240-1253. [CrossRef]

3. Deng, L.; Wang, W.; Yu, Y. State-of-the-Art Review on the Causes and Mechanisms of Bridge Collapse. J. Perform. Constr. Facil. 2016, 30, 04015005. [CrossRef]

4. $\quad$ Proske, D. Bridge Collapse Frequencies versus Failure Probabilities; Springer International Publishing: Cham, Switzerland, 2018. [CrossRef]

5. Zampieri, P.; Zanini, M.A.; Faleschini, F.; Hofer, L.; Pellegrino, C. Failure analysis of masonry arch bridges subject to local pier scour. Eng. Fail. Anal. 2017, 79, 371-384. [CrossRef]

6. Tubaldi, E.; Macorini, L.; Izzuddin, B.A. Three-dimensional mesoscale modelling of multi-span masonry arch bridges subjected to scour. Eng. Struct. 2018, 165, 486-500. [CrossRef]

7. Scozzese, F.; Ragni, L.; Tubaldi, E.; Gara, F. Modal properties variation and collapse assessment of masonry arch bridges under scour action. Eng. Struct. 2019, 199, 109665. [CrossRef]

8. Hulet, K.M.; Smith, C.C.; Gibert, M. Load-carrying capacity of flooded masonry arch bridges. Proc. Inst. Civ. Eng. Bridg. Eng. 2006, 159, 97-103. [CrossRef]

9. Moreira, V.N.; Fernandes, J.; Matos, J.C.; Oliveira, D.V. Reliability-based assessment of existing masonry arch railway bridges. Constr. Build. Mater. 2016, 115, 544-554. [CrossRef]

10. Zentner, I.; Gündel, M.; Bonfils, N. Fragility analysis methods: Review of existing approaches and application. Nucl. Eng. Des. 2017, 323, 245-258. [CrossRef]

11. Kennedy, R.; Ravindra, M. Seismic fragilities for nuclear power plant risk studies. Nucl. Eng. Des. 1984, 79, 47-68. [CrossRef]

12. Mosleh, A.; Jara, J.; Razzaghi, M.S.; Varum, H. Probabilistic Seismic Performance Analysis of RC Bridges. J. Earthq. Eng. 2020, 24, 1704-1728. [CrossRef]

13. Argyroudis, S.A.; Mitoulis, S.; Winter, M.G.; Kaynia, A.M. Fragility of transport assets exposed to multiple hazards: State-of-the-art review toward infrastructural resilience. Reliab. Eng. Syst. Saf. 2019, 191, 106567. [CrossRef]

14. Dong, Y.; Frangopol, D.M.; Saydam, D. Time-variant sustainability assessment of seismically vulnerable bridges subjected to multiple hazards. Earthq. Eng. Struct. Dyn. 2013, 42, 1451-1467. [CrossRef]

15. Banerjee, S.; Prasad, G.G. Seismic risk assessment of reinforced concrete bridges in flood-prone regions. Struct. Infrastruct. Eng. 2013, 9, 952-968. [CrossRef]

16. Yilmaz, T.; Banerjee, S.; Johnson, P.A. Uncertainty in risk of highway bridges assessed for integrated seismic and flood hazards. Struct. Infrastruct. Eng. 2018, 14, 1182-1196. [CrossRef]

17. Kim, H.; Sim, S.-H.; Lee, J.; Lee, Y.-J.; Kim, J.-M. Flood fragility analysis for bridges with multiple failure modes. Adv. Mech. Eng. 2017, 9, 1-11. [CrossRef]

18. Ahamed, T.; Duan, J.G.; Jo, H. Flood-fragility analysis of instream bridges-Consideration of flow hydraulics, geotechnical uncertainties, and variable scour depth. Struct. Infrastruct. Eng. 2020, 17, 1494-1507. [CrossRef]

19. Hung, C.-C.; Yau, W.-G. Vulnerability evaluation of scoured bridges under floods. Eng. Struct. 2017, 132, 288-299. [CrossRef]

20. Argyroudis, S.A.; Mitoulis, S.A. Vulnerability of bridges to individual and multiple hazards-Floods and earthquakes. Reliab. Eng. Syst. Saf. 2021, 210, 107564. [CrossRef]

21. Eidsvig, U.; Santamaría, M.; Galvão, N.; Tanasic, N.; Piciullo, L.; Hajdin, R.; Nadim, F.; Sousa, H.S.; Matos, J. Risk Assessment of Terrestrial Transportation Infrastructures Exposed to Extreme Events. Infrastructures 2021, 6, 163. [CrossRef]

22. Khandel, O.; Soliman, M. Integrated Framework for Assessment of Time-Variant Flood Fragility of Bridges Using Deep Learning Neural Networks. J. Infrastruct. Syst. 2021, 27, 04020045. [CrossRef]

23. Cabanzo, C.A.M.; Ariza, M.P.S.; Sousa, H.S.; e Matos, J.A.C. Reliability-Based Assessment of a Masonry Arch Bridge Under Flood Events. In Proceedings of the 8th International Conference on Computational Methods in Structural Dynamics and Earthquake 
Engineering Methods in Structural Dynamics and Earthquake Engineering, Athens, Greece, 28-30 June 2021; pp. 3377-3388. [CrossRef]

24. Conde, B.; Matos, J.C.; Oliveira, D.V.; Riveiro, B. Probabilistic-based structural assessment of a historic stone arch bridge. Struct. Infrastruct. Eng. 2020, 17, 379-391. [CrossRef]

25. Infraestruturas de Portugal. Modernização da Linha do Norte- Trecho Vila Franca de Xira (Norte)—Azambuja. 2001. Available online: https:/ / www.infraestruturasdeportugal.pt/pt-pt/centro-de-imprensa/modernizacao-da-linha-do-norte (accessed on 8 October 2021).

26. Federal Highway Administration. Hydraulic Engineering Circular Number 18. In Evaluating Scour at Bridges; Federal Highway Administration: Washington, DC, USA, 2001.

27. Marelli, S.; Sudret, B. UQLab: A Framework for Uncertainty Quantification in MATLAB. In Proceedings of the 2nd International Conference on Vulnerability and Risk Analysis and Management (ICVRAM 2014), Liverpool, UK, 13-16 July 2014 ; pp. $2554-2563$. [CrossRef]

28. Pizarro, A.; Manfreda, S.; Tubaldi, E. The Science behind Scour at Bridge Foundations: A Review. Water 2020, 12, 374. [CrossRef]

29. Guimarães, H.; Matos, J.; Henriques, A.A. An innovative adaptive sparse response surface method for structural reliability analysis. Struct. Saf. 2018, 73, 12-28. [CrossRef]

30. Huang, X.; Chen, J.; Zhu, H. Assessing small failure probabilities by AK-SS: An active learning method combining Kriging and Subset Simulation. Struct. Saf. 2016, 59, 86-95. [CrossRef]

31. Nowak, A.; Colins, K.R. Reliability of Structures; CRC Press: Boca Raton, FL, USA, 2000.

32. Ghasemi, S.H.; Nowak, A.S. Reliability index for non-normal distributions of limit state functions. Struct. Eng. Mech. 2017, 62, 365-372. [CrossRef]

33. Appleton, J. History of Arch Bridges in Portugal. In Proceedings of the ARCH 2019, Porto, Portugal, 2-4 October 2020; Volume 11, p. 103. [CrossRef]

34. LimitState: GEO Manual. LimitState: GEO Manual; The Innovation Centre: Sheffield, UK, 2010; Volume 44.

35. Gilbert, M.; Smith, C.C.; Pritchard, T.J. Masonry arch analysis using discontinuity layout optimisation. Proc. Inst. Civ. Eng. Eng. Comput. Mech. 2010, 163, 155-166. [CrossRef]

36. Callaway, P.; Gilbert, M.; Smith, C.C. Influence of backfill on the capacity of masonry arch bridges. Proc. Inst. Civ. Eng. Bridg. Eng. 2012, 165, 147-157. [CrossRef]

37. Amodio, S.; Gilbert, M.; Smith, C. Modelling Masonry Arch Bridges Containing Internal Spandrel Walls. In Proceedings of the 9th International Conference on Arch Bridges, Porto, Portugal, 2-4 October 2019; Springer: Cham, Switzerland, 2020; pp. 315-322. [CrossRef]

38. De Santis, S. Load-Carrying Capability and Seismic Assessment of Masonry Bridges. PhD Thesis, Roma Tre University, Rome, Italy, 2011.

39. Vijayasree, B.A.; Eldho, T.I.; Mazumder, B.S.; Ahmad, N. Influence of bridge pier shape on flow field and scour geometry. Int. J. River Basin Manag. 2019, 17, 109-129. [CrossRef]

40. Kallias, A.N.; Imam, B. Probabilistic assessment of local scour in bridge piers under changing environmental conditions. Struct. Infrastruct. Eng. 2016, 12, 1228-1241. [CrossRef]

41. Nasim, M.; Setunge, S.; Zhou, S.; Mohseni, H. An investigation of water-flow pressure distribution on bridge piers under flood loading. Struct. Infrastruct. Eng. 2019, 15, 219-229. [CrossRef]

42. Johnson, P.A.; Clopper, P.E.; Zevenbergen, L.W.; Lagasse, P.F. Quantifying Uncertainty and Reliability in Bridge Scour Estimations. J. Hydraul. Eng. 2015, 141, 04015013. [CrossRef]

43. Ekuje, F.T. Bridge Scour-Climate Change Effect. Ph.D. Thesis, University of Surrey, Guildford, UK, 2018.

44. Au, S.-K.; Beck, J.L. Estimation of small failure probabilities in high dimensions by subset simulation. Probabilistic Eng. Mech. 2001, 16, 263-277. [CrossRef]

45. JCSS Probabilistic Model Code. Section 3.7: Soil Properties. 2006. Available online: https://www.jcss-lc.org/publications/ jcsspmc/soilproperties_2006.pdf (accessed on 26 September 2021).

46. Zampieri, P.; Zanini, M.A.; Faleschini, F. Derivation of analytical seismic fragility functions for common masonry bridge types: Methodology and application to real cases. Eng. Fail. Anal. 2016, 68, 275-291. [CrossRef]

47. Choudhury, T.; Kaushik, H.B. Treatment of uncertainties in seismic fragility assessment of RC frames with masonry infill walls. Soil Dyn. Earthq. Eng. 2019, 126, 105771. [CrossRef]

48. Su, L.; Li, X.-L.; Jiang, Y.-P. Comparison of methodologies for seismic fragility analysis of unreinforced masonry buildings considering epistemic uncertainty. Eng. Struct. 2019, 205, 110059. [CrossRef]

49. $\mathrm{Wu}, \mathrm{X}$. Trivariate analysis of soil ranking-correlated characteristics and its application to probabilistic stability assessments in geotechnical engineering problems. Soils Found. 2013, 53, 540-556. [CrossRef]

50. Wang, Y.; Akeju, O.V. Quantifying the cross-correlation between effective cohesion and friction angle of soil from limited site-specific data. Soils Found. 2016, 56, 1055-1070. [CrossRef]

51. Xu, C.; Gertner, G.Z. Uncertainty and sensitivity analysis for models with correlated parameters. Reliab. Eng. Syst. Saf. 2008, 93, 1563-1573. [CrossRef] 
52. Pulatsu, B.; Erdogmus, E.; Lourenço, P.B. Influence of soil-backfill depth on the strength and behavior of masonry arch bridges in the transverse direction. In Proceedings of the 13th North American Masonry Conference, Salt Lake, UT, USA, 16-19 June 2019; pp. 15-25.

53. Postacchini, M.; Zitti, G.; Giordano, E.; Clementi, F.; Darvini, G.; Lenci, S. Flood impact on masonry buildings: The effect of flow characteristics and incidence angle. J. Fluids Struct. 2019, 88, 48-70. [CrossRef]

54. NP EN 1990: 2009; Norma Portuguesa-Eurocódigo 0-Bases para o Projeto de Estruturas. Instituto Português da Qualidade: Caparica, Portugal, 2009; Volume 1999, p. 88.

55. Nelder, J.A.; Wedderburn, R.W.M. Generalized Linear Models. J. R. Stat. Soc. Ser. A 1972, 135, 370. [CrossRef]

56. Pulatsu, B.; Erdogmus, E.; Lourenço, P.B. Comparison of in-plane and out-of-plane failure modes of masonry arch bridges using discontinuum analysis. Eng. Struct. 2019, 178, 24-36. [CrossRef]

57. Lin, C.; Han, J.; Bennett, C.; Parsons, R.L. Case history analysis of bridge failures due to scour. In Climatic Effects on Pavement and Geotechnical Infrastructure-Proceedings of the International Symposium of Climatic Effects on Pavement and Geotechnical Infrastructure; American Society of Civil Engineers: Reston, VA, USA, 2014; pp. 204-216. [CrossRef] 